\title{
The impact of silo mentality on team identity: An organisational case study
}

Authors:
Frans Cilliers ${ }^{1}$
Henk Greyvenstein ${ }^{1}$
Affiliations:
'Department of Industrial
and Organisational
Psychology, University of
South Africa, South Africa
Correspondence to:
Frans Cilliers
Email:
Cillifvn@unisa.ac.za
Postal address:
PO Box 392, UNISA 0003,
South Africa
Dates:
Received: 31 May 2011
Accepted: 23 Nov. 2011
Published: 22 Mar. 2012
How to cite this article:
mentality on team identity:
An organisational case study.
SA Journal of Industrial
Psychology/SA Tydskrif vir
Bedryfsielkunde, $38(2)$, Art.
\#993, 9 pages. http://dx.doi.
org/10.4102/sajip.v38i2.993

C 2012. The Authors Licensee: AOSIS OpenJournals. This work is licensed under the Creative Commons Attribution License.
Orientation: Organisational silos do not only refer to conscious structures, but also to an unconscious state of mind and mentality that takes on a life of its own. Silos result in the splitting of organisational artefacts and relationships, and impact negatively on relationship forming between individuals and within teams.

Research purpose: The purpose of this research was to describe how the silo mentality impacts on team identity.

Motivation for the study: During a recent organisational consultation the researchers realised that a so-called silo phenomenon had much more unexplained unconscious behaviour than was traditionally realised in terms of organisational development. It is hoped that findings from this qualitative study could give consultants entry into what happens below the surface in the silos' unconscious.

Research design, approach and method: A qualitative and descriptive research design using a case study strategy was used. Data gathering consisted of 25 narrative interviews. Using discourse analysis four themes manifested, integrated into four working hypotheses and a research hypothesis. Trustworthiness and ethical standards were ensured.

Main findings: Themes that emerged were the physical environment and structure, intragroup relations, experiences of management, and intergroup relations.

Practical/managerial implications: Consulting on silo behaviour as physical structures only may not be successful in changing organisational behaviour. The silo resembles an iceberg the largest part is below the surface.

Contribution/value-add: The findings evidenced silo behaviour to be an unconscious phenomenon influencing team identity negatively. Consultants are urged to study these manifestations towards understanding silos and their effect on team identity better.

\section{Introduction}

We have all heard jibes such as 'Oh don't bother trying to find HR after four o'clock ...' or 'Senior management still has no clue what's really happening on the plant!'. Inherent to any hierarchical organisation is a vertical and horisontal specialisation which is often looked upon with disdain, and which contains to-and-fro projections across boundaries (Vansina \& Vansina-Cobbaert, 2008). The vertical specialisation exists between the various functional areas, such as production and marketing, whilst the horisontal segmentation exists between the positional power levels of leadership, management and employees. To understand the depth psychology of organisational silos necessitates an appreciation of the unconscious dynamics and symbolism inherent in silos (whether vertical or horisontal), and how this influences the formation of team identity.

Group and organisational identity are well researched in different fields of specialisation, including marketing (Amy, 2002; Gupta \& Ogden, 2009; Grier \& Rohit, 2001), education (Hartnett, 2007; Gurim \& Nagda, 2006; Stark-Rose, Lokken \& Zarghami, 2009), anthropology (Torres-Rouff, 2008), sociology (Wade \& Brittan-Powell, 2000; Yount, 2004; Heaven, 1999a; Purdie-Vaughns \& Eibach, 2008; Swann, Kwan, Polzer \& Milton, 2003) and psychology (Anthony, 2005; Lipponen \& Leskinen, 2006; Mali, 2006; Noels \& Clement, 1996; Heaven, 1999b; Volkan, 2009). Organisational psychology yields a substantial amount of research in this field (Randel, 2002; Hatch \& Schultz, 2002; Meyer, Bartunek \& Lacey, 2002), mostly conceptualised from the humanistic view.

Research on group and organisational identity often regard the two constructs as being similar. This is evident in the work of Blombäck and Brunninge (2009), He and Baruch (2009), Kovoor-Misra (2009), Reza (2009) and Sato (2010), where the literature on group identity implies organisational behaviour. This is seldom the case the other way around. Both group and organisational identity 
are well differentiated from individual behaviour (Diamond \& Allcorn, 2009). This research approached the impact of silo behaviour on team identity from a meso (group) perspective, as distinct from an individual (micro) or organisational (macro) perspective.

Volkan defines group identity as 'the subjective experience of ... people linked by a persistent sense of sameness' (2009, p. 6). This view resonates with Whetten's seminal work on organisational identity, where the latter is defined as 'the central and enduring attributes of an organisation ...'; '... that distinguishes it from other organisations' (2006, p. 220). This definition incorporates a phenomenological component where any identity-related inquiry 'was most likely to be observed in conjunction with profound organisational experiences' (Whetten, 2006, p. 220). This implies that the construct of team identity refers to rational and conscious organisational behaviour.

The concept of organisational silos is often used in practice but has not been thoroughly researched. It is thought that Neebe (1987) made the first reference to silos as a metaphor in organisational behaviour, with reference to grain silos as an example of how parts of organisations function in a manner disconnected from the others. The general organisational psychology literature refers to the concept based on the traditional view and mechanistic manner in which organisations are structured (Diamond \& Allcorn, 2009; Head, Yaeger \& Sorensen, 2010; Stone, 2004; Sy \& Cote, 2004; Weisbord \& Janoff, 2005). This implies a hierarchical organisation structure whereby positions flow downward - vertically, from those with the most organisational power and authority, to those with the least. These are typically depicted on an organisational chart or organogram.

The top most position carries definitive responsibility for the organisation's performance along with ultimate decisionmaking power and final authority (Greenberg \& Baron, 2003). As one descends the hierarchy, decision-making power and authority diminish to the point where employees have little if any authority (Hirschhorn, 1997). The above literature also distinguishes vertical areas of functional specialisation, where organisations' horisontal axes are divided into specialised divisions and manageable work groups (e.g. marketing, human resources, legal, operations, production, research and development).

Traditionally the organisational psychology literature views silos as conscious, rational and objective entities. Yet the effect of silo behaviour seems to relate also to behaviour happening below the surface (see Huffington, Armstrong, Halton, Hoyle \& Pooley, 2004) in terms of its unconscious, irrational, symbolic and representative meaning, implications and impact.

This led researchers to systems psychodynamics as a paradigm to investigate such unconscious dynamics. This theory is based on classic psychoanalysis (Freud, 1921), object relations
(Klein, 1948, 1997), open systems theory (Von Bertalanffy, 1968), social systems as defences against anxiety (Jaques, 1970; Menzies, 1993), group relations theory (Bion, 1961) and various relevant dynamic constructs (Cilliers, 2005; Cilliers \& Koortzen, 2005). Generally, organisational psychodynamics can be defined as the study of unconscious patterns of work relations (Adams \& Diamond, 1999) and their influence on leadership, role formation, conflict, identity, boundaries and authority. Such unconscious patterns include ego defence mechanisms like splitting, where the subject gains relief from internal conflicts by peeling off (usually negative, unwanted) parts of the self as if they were not of the self, and projection, whereby these split-off parts are attributed to another to carry on behalf of the subject, thereby providing containment for its own anxiety (Czander, 1993; Hinshelwood, Robinson \& Zarate, 1997; Klein, 1997). Such behaviour can also be understood against Bion's framework for analysing the irrational features of unconscious group life, consisting of dependency, fight and/or flight, pairing (Bion, 1961) and, more recently, also 'one-ness' (Turquet, 1974) and 'we-ness' (Gabelnick \& Carr, 1989; Hirschhorn, 1988).

The purpose of this research was to describe how silo mentality impacts team identity. Whereas group and/or team identity as well as silo behaviour have been studied in organisational psychology from different paradigms, the effect of what is referred to as silo mentality in systems psychodynamic thinking has never been linked to team behaviour or identity forming. The research objectives were to explore the meaning of silo mentality from a systems psychodynamic stance, to describe a case study in terms of its silo behaviour and to present a hypothesis of how silo mentality influenced the team identity in this organisational system as a guideline for consultants working in the area.

The psychodynamic view of organisations holds that, apart from their conscious and physical aspects, organisations also exist in the unconscious minds of people. This construct is referred to as the 'organisation-in-the-mind' (Armstrong, 2005; Turquet, 1974) and contains the individual and collective fantasies and projections in and about the workplace (Czander, 1993; Gabriel, 1999; Gould, Stapley` \& Stein, 2001).

Collective meaning and identity are given to these unconscious fantasies and emotions through exploring and studying intrapersonal and intra-subject object relational patterns. By doing so meaning is derived about organisations. Therefore, to know, understand and appreciate an organisation, more than traditional behavioural, empirical and positivistic analysis methods are required (Gould, Stapley \& Stein, 2004; Hirschhorn, 1988; Huffington et al., 2004). Unconscious patterns of relations between individuals and their image of the organisation-in-the-mind need to be elicited.

Since the 1950s most organisations have been structured hierarchically (Greenberg \& Baron, 2003). Typically an organisation would have layers of positions flowing 
downward from the top position with the most power and influence to those at the bottom with less. Another characteristic is the vertical areas of specialisation - human resources (HR), marketing and operations. Hence horisontal and vertical silos are created. As parts of the organisation, silos too are in-the-mind and have their own unconscious patterns of relations between individuals. As an image of the organisation-in-the-mind, silos influence work behaviour (Diamond \& Allcorn, 2009).

Mainstream literature on organisational behaviour (Greenberg \& Baron, 2003) uses the silo metaphor to denote organisation dysfunction and fragmentation. It refers to feelings of disconnection - the left hand not knowing what the other is doing, stuckness, isolation and powerlessness, lack of trust, respect, collaboration and collegiality. The image is one of silos in opposition internally or with other silos. Allcorn, Diamond and Stein introduced silos as an organisational metaphor in the systems psychodynamic literature (Diamond \& Allcorn, 2004, 2009; Diamond, Stein \& Allcorn, 2002; Diamond, Allcorn \& Stein, 2004). They defined organisational silos as vast psychological spaces of compartmentalisation, segregation and differentiation.

Psychodynamically, silos represent the phallic characteristics of male dominance, submission and persecution. They are characterised by intra- and intergroup anxiety followed by the infantile and regressive defensive structures of splitting (dividing the external world into good and bad objects), introjection (taking the good into one's inner reality), projection (putting the bad onto the other), and projective identification (putting the bad onto the other with the unconscious intent of using, coercing or manipulating the object). This has consequences for work performance on the personal, group and/or team and organisational levels - the micro, meso and macro levels. Thus, silos become a splitin-the-mind, serving as an invisible barrier to contain the collective unconscious team and organisational fantasies and emotions.

It can be hypothesised that through studying the unconscious silo behaviour in organisations, important information can be gained about what the silo represents for the team (what keeps the silo intact), how teams struggle to find their identity, and to differentiate between the within silo and outside of the silo aspects of identity.

\section{Silo as invisible barrier}

Silos are not really physically present in organisations they exist in the mind of employees who have a shared impression of its reality (Diamond \& Allcorn, 2004, 2009). In the mind, they provide safety and comfort by keeping the others out, those who are 'not like us'. In doing so, silos as barriers fragment organisations. These barriers create an 'us and them' mentality which makes boundary crossing difficult, and often causes major anxiety in employees having to attend meetings with or visiting other departments, sites or teams.
These various parts of the organisation become delineated to the extent that those inside feel threatened by those outside the invisible barrier and view them with suspicion, fear and disdain (Diamond et al., 2004). When teams or groups exhibit silo mentality it refers to a position where systemic thinking and the vision of the larger organisation are absent (Burge, 1993). In the unconscious such denial of a part of the whole brings about splitting, usually followed by projection and high levels of free-floating, survival and persecutory anxiety (see Blackman, 2004).

\section{Silo as container}

As container, silos serve to facilitate primitive reaction forms of fight and flight - fight whatever is outside and flee to the inside of the container with its presumed safety (Czander, 1993). This represents the paranoid-schizoid position (Klein, 1948) and object-to-object communication in that the container as an invisible barrier furthers 'us and them' fragmenting. As a container, the silo enables group-think, which indicates the presence of basic assumption we-ness. We-ness leads to self-aggrandisement as a defence, which further supports the notion that 'everything out there is bad and everything in here is good'. To be the container and the contained at the same time leads to silo inhabitants becoming all-knowing and manic (see Huffington et al., 2004).

In sum, silos represent a near-absence of depressive wholeobject connections and are dominated by paranoid-schizoid part-object experiences (Diamond \& Allcorn, 2009). Through reification, the silo itself is seen as the source of the experiences rather than its projective surface (Blackman, 2004), often followed by introjection and projective identification where employees in the silo take that silo inside of themselves and think of themselves as teams, departments or sections, unaware of a whole - as if it does not exist. The purpose of the reification is to assure silo members that the problem is outside rather than inside and related to themselves (Diamond \& Allcorn, 2009). In the mind, the team in a silo then becomes the whole. Important to note is that whether for the silo or for a part of the silo, the same dynamic manifests, such as for an organisational development (OD) team within an HR silo.

A single team or group will also feel safe within the team and view the other silos and teams in the organisation not just as the other, but as the enemy other - to be distrusted, feared and fought. The bad in the mind (such as the incompetent, not understanding, infighting, slow to react) is then split off and projected onto those silos or teams, for them to carry. The team then becomes the whole seeing itself as only good, and the centre and reason for existence of the entire organisation. In terms of its own identity (its central and enduring attributes that distinguish it from other teams), the team will then assume attributes of omnipotence, camaraderie and knowledge. Silo mentality can therefore be described as a phenomenon where employees unconsciously treat (perceive and act) the organisation, and those in other departments and divisions, as part-objects (see Diamond \& Allcorn, 2009). 
The research problem was formulated as follows: How does the presence of the silo mentality impact on a team's sense of identity? The research objectives were to describe and understand silo mentality and to hypothesise how this impacted on a specific team's identity.

No evidence of previous research findings studying the effect or impact of silo behaviour on team functioning or identity could be traced. This research could therefore be seen as a contribution towards extending the knowledge around this impact, and specifically within the South African context. As such it could assist organisational psychologists and consultants to understand the underlying dynamics manifesting in their client systems whenever there is a tendency to silo-ing.

The research design is presented next, with reference to the research approach and strategy. This is followed by a description of the research method, consisting of the setting, roles of the researchers, sampling method, data collection, recording and analysis. Lastly, strategies employed to ensure quality data are outlined. Thereafter the findings are presented in four themes. In the discussion the findings are integrated in the research hypothesis, which is followed by the conclusion, recommendations, limitations and suggestions for further research.

\section{Research design Research approach}

Qualitative research was used (Camic, Rhodes \& Yardley, 2003), set within psychosocial organisational studies (Clarke, 2006) and organisational anthropology (Levinson, 2002). The research position allowed for application of a cluster of methodologies, working beyond the purely discursive and beneath the surface (Clarke \& Hoggett, 2009). As epistemology, the hermeneutic interpretive stance was used (Geertz, 2000), which allowed for rich and meaningful interpretations of the observed occurrences (Alexandrov, 2009).

\section{Research strategy}

A departmental case study (Chamberlayne, Bornat \& Apitzsch, 2004) with three sub-cases was used to investigate the phenomenon of silo behaviour empirically in a reallife context (Creswell, 2003). Sub-case analysis was used to facilitate individual understanding, followed by cross-case analysis and the emergence of themes (Hollway \& Jefferson, 2010) for the department as a whole (Wells, 1980). This allowed for an in-depth examination of the manifesting behaviours from multiple sources of information (Creswell, 2003). This strategy was seen as intrinsic to gain an understanding of the organisation's dynamics and instrumental to building the knowledge base on silo behaviour (Denzin \& Lincoln, 2005; Stake, 1995).

\section{Research method \\ Research setting}

The research was set in a large corporate head office in Gauteng, specifically one department rendering a technical service to internal clients. A project team, which consisted of the head of the OD division, the departmental manager and the first researcher, was tasked to investigate the department's declining performance rating.

\section{Entrée and establishing researcher roles}

The first researcher was authorised by the organisation to take up the role of consultant (Lowman, 2002) and researcher (Alexandrov, 2009). During data collection he took the role of interviewer (Alvesson \& Sköldberg, 2010), and during the analysis the role of systems psychodynamic consultant (Neumann, Kellner \& Dawson-Shepherd, 1997). The first and second researchers were involved in the data analysis, interpretation and integration.

\section{Sampling}

Opportunistic sampling was used (Terre Blanche, Durrheim \& Painter, 2006). The department as an organisational case study consisted of three cases, namely the manager $(N=1)$, his staff $(N=14)$ and two representatives each from five internal client departments $(N=10)$. The manager was a 55-year-old White male with 30 years' experience in this organisation. The 24 staff members were all technically qualified and almost equally distributed in gender and race, with a mean age of 38 years.

\section{Data collection method}

A one-hour, unstructured, individual narrative interview was used (Clarke \& Hoggett, 2009). This took place in a boardroom in close proximity to the department's location. The interview started with the question: 'What is it like to be a member of this department?' (see Diamond \& Allcorn, 2009). Hereafter the interviewer responded to the respondents' ordering and phrasing - carefully listening in order to make follow-up comments using the respondents' own words and phrases without offering interpretations, becoming an almost invisible facilitating catalyst to the respondents' stories (Hollway \& Jefferson, 2010).

\section{Recording of data}

The interviews were tape-recorded. Afterwards the first researcher used 10 minutes to add data around the participant's body language, ambiance in the room, and his own subjective experience during the interview (see Van Manen, 1990). The data were transcribed and stored safely.

\section{Data analyses}

Discourse analysis was used (Breverton \& Millward, 2004; Cilliers \& Smit, 2006). Simple hermeneutics allowed for the understanding of individuals' subjective and inter-subjective reality and meaning, and double hermeneutics facilitated critical interpretation of unconscious processes from the 
systems psychodynamic stance (Clarke \& Hoggett, 2009). The assumption was that unconscious communication dynamics and defences influence subjects' construction of their reality (Alvesson \& Skoldberg, 2005; Hunt, 1989).

\section{Strategies employed to ensure quality data}

Ethicality (Terre Blanche et al., 2006) was assured by formally contracting the consulting and research activities with the head of the OD division, the departmental head, and individual participants. This included voluntary participation, informed consent and confidentiality of shared data. In terms of the research project, ethicality was ensured through thorough design, planning, conducting and analysis of the interviews, presentation of the data in this document and feedback to the head of the OD division.

Trustworthiness is based on validity and credibility (Denzin \& Lincoln, 2005). The study evidenced strong and believable validity in its depth psychological description, which revealed the complexities of the systems' defensive behaviours. The interpretations were peer-reviewed (Brewerton \& Millward, 2004) by an independent systems psycho-dynamically informed psychologist, who evaluated the dependability and saturation of the findings favourably. Credibility was assured in the competence of the researchers - both are trained in systems psychodynamic consulting and research (according to the requirements stated by Brunner, Nutkevitch \& Sher, 2006).

\section{Reporting}

The findings are reported according to discourse theme. In the discussion working hypotheses (Terre Blanche et al., 2006) are formulated for each theme, integrated into the research hypothesis (Schafer, 2003). Finally, the conclusion, recommendations, limitations and suggestions for future research are presented.

\section{Findings}

Four themes manifested namely, (1) physical environment and departmental structure, (2) intra-group relations, experiences of management and (4) intergroup relations.

\section{Physical environment and departmental structure}

The department was situated in the basement of a large midtown building, filling a large open-plan space, with boxes of green plants between workstations. Participants described their work environment as 'our space', 'where we can be different/like fish in water', 'we need to be separate' and 'out of the way', 'even though we feel forgotten sometimes'. Participants voiced their resistance to a rumour that the department would move to another part of the building by saying 'that would frustrate us', 'will expose us to the noise in the business', 'we will get sucked into the politics there', 'it will lead to chatting' and 'time wasted'. Some of the younger participants called the basement 'the dungeon', 'where we hide' and 'pretend that we are the world'. Participants were clear about the departmental strategy, structure, primary task and job content. One participant remarked that the departmental structure 'keeps people hostage', whilst another made a (Freudian) slip, referring to 'my colleague's parole', whilst referring to his promotion.

\section{Intra-group relations}

Participants described their work performance as follows: 'we are specialists', 'proud of our work' and delivering a 'remarkably efficient' and 'surprisingly effective service'. They mentioned that 'we are well trained', have 'state of the art' technical equipment and electronic hard- and software. Participants described their work relationships amongst the team members, excluding the manager, as 'positive/calm/ serene/friendly/helpful/creative' and the nature of the internal relationships as 'united/secure/together/cohesive', 'almost spiritual', and 'like a family'.

\section{Experiences of management}

The departmental manager was described positively by some participants in terms of his 'intelligence', 'good corporate insight' and 'extroversion'. Thereafter, all participants described him in an extremely negative way as emotionally immature, inflexible, rigid, not trustworthy, defensive, moody and with little insight into his own behaviour. His management style was described as centralised, making all the decisions, controlling, enforcing his view, pretending to care and listen but not doing so, making people dependent, disempowering and confusing them, managing by fear, causing stress, derailing our work and creating animosity amongst us with his double messages and 'contradictions'. One participant said 'he is dangerous because he is unaware of his impact on people'. His department experienced stress; people said they were 'living in fear', anxious 'to not make mistakes', feel 'like being on a rollercoaster', 'not getting recognition', 'don't have work-life balance', and the department 'is in serious need of team building' and integration. One participant said that 'we have learned to work around him'.

During his own interview the manager was apprehensive about the interviews and the involvement of the head of OD in the project. He defensively justified his behaviour, often using numbers and figures to strengthen his arguments. He was nervous and tried to sell himself as a good and caring manager, whilst at the same time not listening to the interviewer's inputs. He created an image of independence, aloofness and detachment as if he feared being out of control. He voiced his inputs in a grandiose manner by referring to 'my department that I have built up over 12 years', 'my very sophisticated equipment' and to the staff as 'my family that I have picked by hand'.

\section{Intergroup relations}

The department's experience of their internal client is negative. In terms of work performance, participants referred to the client managers as 'not being skilled' and the 
staff as 'they don't know what they do', 'don't take pride in their work', 'they have no realisation of time', 'always do last minute changes', 'supply incorrect information', and 'deliver poor and incomplete demands'. In terms of behaviour on the boundary with the client, participants said 'they don't understand our work/what we do/how we think', 'they don't know what to do with us/how to handle us', 'we only see them when they demand something', 'they put pressure on us', 'they always demand', 'they compete with us/don't respect us/treat us with hostility/appreciation', 'treat us like idiots', and 'they anger and frustrate us'.

The client's experience of the department always started with a positive remark - and was immediately followed by an outpouring of negative aspects. Positively, the department is giving 'excellent service', produces 'effective work/has good delivery', has 'their procedures in place', 'maintains deadlines', 'gives quality', 'renders good client service', and 'the work gets done'. They described the departmental staff as 'well qualified', 'skilled', and 'working hard'. These positive remarks were followed by negative comments about the department's management, work performance and behaviour. The department's management was experienced as 'poor', ineffective and 'not providing a clear strategy/direction', and 'we are not sure of what we are working towards'. Management is 'not available', 'don't provide resources' and can't ensure that their staff have the 'relevant skills to service us'. Projects are 'mismanaged' in terms of planning, control, tracking and feedback. 'Their work processes are ambiguous', 'they demand impossible deadlines' and 'the matrix lines' through which the department and the business related 'are filled with difficulties' resulting in 'a disconnection'.

Their work performance 'has been going down over time', 'they don't know what they do', 'they are incompetent', 'they are getting used to the same old thing', 'their work has become rigid over time', 'they misinterpret instructions', 'the pace has become slower due to volume', 'there are delays/slackness / bottlenecks', 'there are limited updates about progress or changes'. Their work 'has become inconsistent', for example, when 'they prefer to service the more corporate glamorous/ affluent parts of the business' when 'our requests were first and more urgent', 'they have become risk/change averse', 'they have tunnel vision' and 'there is a lack of transparency' in how they operate. Some people 'do not make sure they get the correct information', sometimes they 'report our mistakes to management', 'they gossip about us', 'get us into trouble with our bosses', 'act behind our backs' in 'collusion with my line manager', to the extent that 'the information will then unexpectedly pop up in my performance discussion'.

The department's behaviour is 'negative', 'not good at all', 'they think they are in charge of us', 'some people highjack information and power', 'they act defensive', 'they use power to control us', 'they use emotional power over us', 'we handle them with gloves' because 'we are afraid that we may sound confrontational'. The relationship is 'unfriendly', 'it feels like a madam and servant talking', 'it is as if they only think of themselves', 'we often have to stand on our knees, begging', 'you need to be very careful in how you communicate', 'we often are fearful when we enter the basement', 'you feel as if you hit an iron wall'. It was also stated that 'all kinds of negative feelings are between us' such as 'irritation/anger/ frustration/jealousy'.

An additional dynamic manifested amongst seven young Black women amongst the client participants. During the interviews they appeared hurried, rushed and uninterested, saying 'I am only here to work', 'if they can just leave me alone', 'I am doing my best', 'I need to get along with everyone', and 'I don't want to get involved in the politics'. Halfway through their interviews, three of these participants asked the researcher 'can I go now - I need to get back to my desk'. Four participants volunteered information about being the first in their families to have tertiary education and to work in a corporate environment. They spoke about their exhaustion, a sense of 'losing myself', 'not knowing why I am here' and of thinking of resigning. Their stories revealed that they have approached their corporate careers with excitement, curiosity and hope - idealising the corporate world and its promises of endless opportunities. Their previous positive experiences have disappeared, their energy was depleted and they appeared disillusioned and even burnt-out.

\section{Discussion}

The purpose of this research was to describe how silo mentality impacts on team identity. The research is important in that it reveals that manifestations of unconscious defensive structures in the organisation act as symptoms of silo mentality. The findings also illustrate how the silo mentality plays such a significant part in identity forming. Themes that emerged from the findings were the physical environment and departmental structure, intra-group relations, experiences of management, and intergroup relations.

\section{Theme 1: Physical environment and departmental structure}

The first theme evidenced the department's basic assumption functioning (Bion, 1961). It split the clear techno (structure) from the troubled socio (relationship) aspects (Miller, 1993). The system was obsessively dependant on its boundaries of separateness. In their flight into one-ness, the basement became their boundary in the mind (Lawrence, 1999) - their fantasised, safe, detached and untouchable silo-bunker (as a psycho-geographical silo - see Stein, 1987). Here they experienced inner support, protection and preservation, but also imprisonment; and outer incompetence characterised by noise, politics and time wastage. The department used the primitive defences (Blackman, 2004) of splitting off the bad and owning the good, regression (into the basement), resistance (staying in the basement), introjection (of the good and their preservation), projection (of the incompetence) and flight (away from the other) (Vansina \& Vansina-Cobbaert, 2008). 


\section{Working hypothesis 1}

The system functioned in a split between light, represented by the technical and/or structure, and darkness, represented by the poor human relations in the basement. It has introjected a prison-like smugness, authorised (Hirschhorn, 1997) by self-righteousness, and projected its incompetent shadow onto the other, who identified with the projection. The use of primitive defences indicated the system's experience of being under attack (probably by the manager), which explains the need to hide in the basement with limited social connections. These unconscious dynamics lead to the department's primary role as service rendering being denied and de-authorised, which manifested as off-task survival, to the point of self-imprisonment.

\section{Theme 2: Intra-group relations}

This theme evidenced the department's extreme introjected goodness in terms of tasks and relationships. Their relationships were characterised by a flight into one-ness almost to the point of incestuous cohesion (Gutmann, 2003). The boundary around the department (excluding the manager) was tightly contained, almost impenetrable, and their relatedness inside was idealised to the point of becoming a spiritual sanctuary (see Lawrence, 1999).

\section{Working hypothesis 2}

The system functioned in extreme one-ness characterised by the preservation of goodness elevated into a fantasy of holiness.

\section{Theme 3: Experiences of management}

The theme was evidenced by the departmental staff's strong negative experiences of the manager, and their attack on his management and personal style (with a few less personal cognitive aspects framed as positive). It was as if the staff put a clear boundary between themselves and the manager. On the inside (according to theme 2) they associated themselves with and have introjected love (Eros), whilst they have excluded and dissociated themselves from the manager and projected their aggression (Thanatos) onto him (Cytrynbaum \& Noumair, 2004). Consciously the manager presented himself as a clever, strong and well-managing hero. Unconsciously he defended against his anxiety (Blackman, 2004) through denial (of staff's hate), detachment (being out of touch), projection (making the head of OD the enemy), suspicion (making the interviews the enemy), compensation (presenting himself as hero), rationalisation (explaining) and narcissism (referring to his possessions and people) (Obholzer \& Roberts, 1994).

\section{Working hypothesis 3}

In the split between staff and manager, the staff attached to the good and denied and detached from the bad, living safely in a utopian fantasy. As staff could not identify with the manager's style, he became the target of their projection of all bad. It was as if the manager was emotionally taken hostage and given an impossible (double) task of containing the bad as well as denying it in trying to keep up appearances.

\section{Theme 4: Intergroup relations}

This theme was evidenced by intergroup conflict between the department and its clients, with to-and-fro projections of incompetence (Campbell, 2007). The client system's limited positivity illustrated their dependence (as client). The discourse of the seven Black females indicated how they as a subsystem identified with the projections of attack and became the container of detachment. It was as if they became the representation of the obliterated, burnt-out ashes of the system.

\section{Working hypothesis 4}

The intergroup dynamic in the system is fraught with splits and projections as if the war was in a deadlock, causing extreme emotional confusion and exhaustion. The Black women represent the hopelessness in the fight.

\section{Silo mentality}

The findings strongly suggested the manifestation of silo mentality in this organisational case study (see Diamond \& Allcorn, 2009; Stein, 1987). The employees treated one another as part-objects as if they were the whole, as a defence against not coping with the integrated organisation-as-whole and its systemic complexity and hostility (see Wells, 1980). High levels of anxiety created defences which formed invisible barriers in and between subsystems and in the mind. The silos manifested horisontally in the aggressive split between staff and manager and vertically between the department and the internal client.

The discourse was filled with metaphors of danger, hostagetaking, dominance and control, opposition, isolation, stuckness, imprisonment, inclusion-exclusion, separation, segregation, compartmentalisation, differentiation, fragmentation, lack of collaboration, denigration and the balkanisation of parts. The manifesting primitive defensive behaviours were split (between owning and not-owning), projection, projective identification, detachment, regression and resistance (Campbell \& Huffington, 2008). As a 'silo within a silo' the White male manager and the Black females mirrored one-another's behaviour as evidence of how the system brought diverse opposites together through aggression. It was hypothesised that the silo mentality acted as: (1) an invisible boundary between the self and the other; as well as (2) a container of safety for the self and protection against the hostile other (Klein, 2005).

\section{Team identity}

The findings strongly suggested a team identity characterised by high levels of anxiety and basic assumption functioning (Bion, 1961; 2003). As a whole, the system was caught up in its dependence on territory and toxicity (Fox \& Spector, 2005) followed by counter-dependence manifesting as projections 
of aggression. The department was fighting the enemies-inthe-mind as well as their own projected identification around incompetence. They used flight into fantasies of security and competence as a defence against their experienced threat and chaos (Campbell \& Gronbaek, 2006). The team's we-ness was manifesting in an extreme spiritual and familial togetherness, as an indication of how strong the sense of threat was. It was hypothesised that their behaviour of we-ness was based on guilt (Speziale-Bagliacca, 2004) and/or a sense of delusional grandiosity (Schwartz, 1990). In his isolated superiority, the manager played out the systemic me-ness.

The above basic assumption functioning was supported by defence mechanisms (Blackman, 2004; Klein 2005), namely, resistance (to relinquish the image of superiority, creativity), splitting (of task and relationships), introjection (of own beliefs about the self), introjective identification (which hindered their objectivity about reality), splitting off and projection (of incompetence), and regression (into family dynamics of rebellious children).

From a systems psychodynamic role-analysis perspective (Newton, Long \& Sievers, 2006), the team's identity was interpreted as follows (Obholzer \& Roberts, 1994). The normative role was relatively clear, although negatively influenced by the projections from the client. The experiential role contained the team's introjected poor-child ego state of not being cared for and having to grow up alone (James, 1977) and the manager's all-knowing and competent parental ego state. These two states functioned as the base of the split in the relationship. The phenomenal role of the staff contained strong projections of incompetence from the client, the manager from the staff and the young Black women from the whole system.

The team's identity can be summarised as a detached, actingin and autistic differentiation (Czander, 1993; Gould et al., 2001; Stapley, 2006) stuck in its own confined, demarcated and schizoid mindspace. Silo mentality is described in the same manner.

The research hypothesis was formulated as follows: the silo mentality with its destructive splitting into the compartmentalisation of part objects, impacted negatively on team identity and manifested in similar symptoms of destructive, autistic and schizoid functioning. The silo mentality acted as a defence against mature connection between people.

It was concluded that silo mentality and a disengaged team identity are similar in their destructive differentiation and breaking down of connection. Both showed the characteristics of the paranoid-schizoid position with its object-object relations, thus keeping the system in basic assumption functioning.

It is recommended that organisational psychologists and consultants take note of the destructive impact of silo mentality on team identity, the breaking down of connections, relationships and relatedness for not only the part object, but presumably for the whole organisation. It is recommended that role analysis be used in a formal consulting project for teams such as these. This may replace the narrowly specialised single mindset (Kaeter, 1993) towards an integrated and well-connected system.

Limitations of this research relate to the use of one collective case study. If more cases in the same organisation were used, a clear idea of the organisational climate and culture could have been integrated into the findings.

It is suggested that future research focuses on replicating this study in other organisations and settings for comparison and towards the building of knowledge across organisational types.

\section{References}

Adams, G.B., \& Diamond, M.A. (1999). Psychodynamic perspectives on organizations: identity, politics and change. American Behavioral Scientist, 43(2), 221-224. $\mathrm{http}: / / \mathrm{dx}$.doi.org/10.1177/00027649921955227

Alexandrov, H. (2009). Experiencing knowledge: the vicissitudes of a research journey In S. Clarke \& P. Hoggett (Eds.), Researching beneath the surface. Psycho-social research methods in practice (pp. 29-49). London: Karnac.

Alvesson, M., \& Skoldberg, K. (2010). Reflexive methodology. New vistas for qualitative research. London: Sage.

Amy, E.R. (2002). Identity salience: A moderator of the relationship between group gender composition and work group conflict. Journal of Organizational Behavior, 23(6), 749. http://dx.doi.org/10.1002/job.163

Anthony, D. (2005). Cooperation in Microcredit Borrowing Groups: Identity, Sanctions, and Reciprocity in the Production of Collective Goods. American Sociological Review, 70(3), 496

Armstrong, D. (2005). Organization in the mind: Psychoanalysis, group relations, and organizational consultancy. London: Karnac Books.

Bion, W.R. (1961). Experiences in groups. London: Tavistock Publications. http:// dx.doi.org/10.4324/9780203359075

Bion, W.R. (2003). Learning from experience. London: Karnac.

Blackman, J.S. (2004). 101 Defences. How the mind shields itself. New York: BrunnerRoutledge.

Blombäck, A., \& Brunninge, O. (2009). Corporate identity manifested through historical references. Corporate Communications, 14(4), 404. http://dx.doi. org/10.1108/13563280910998754

Breverton, P., \& Millward, L. (2004). Organisational research methods. A guide for students and researchers. London: Sage.

Brunner, L.D., Nutkevitch, A., \& Sher, M. (2006). Group relations conferences. Reviewing and exploring theory, design, role-taking and application. London: Karnac.

Burge, F.J. (1993). Silo commanders and the enterprise-wide vision. Electronic Business Buyer, 19(10), 188.

Camic, P.M., Rhodes, J.E., \& Yardley, L. (2003). Qualitative research in Psychology. Washington: APA.

Campbell, D. (2007). The socially constructed organisation. London: Karnac.

Campbell, D., \& Gronbaek, M. (2006). Taking positions in the organisation. London: Karnac.

Campbell, D., \& Huffington, C. (2008). Organisations connected. A handbook of systemic consultation. London: Karnac.

Chamberlayne, P., Bornat, J., \& Apitzsch, U. (2004). Biographical methods and professional practice. An international perspective. Bristol: Policy Press.

Cilliers, F. (2005). Executive coaching experiences. A systems psychodynamic perspective. South African Journal of Industrial Psychology, 31(3), 23-30.

Cilliers, F., \& Koortzen, P. (2005). Working with conflict in teams - the CIBART model. HR Future, October, 52

Cilliers, F., \& Smit, B. (2006). A systems psychodynamic interpretation of South African diversity dynamics: a comparative study. South African Journal of Labour Relations, 30(2), 5-18.

Clarke, S. (2006). From enlightenment to risk: Social theory and contemporary society. New York: Palgrave Macmillan.

Clarke, S., \& Hoggett, P. (2009). Researching beneath the surface. Psycho-social research methods in practice. London: Karnac.

Creswell, J.W. (2003). Research design: Qualitative, quantitative and mixed methods. London: Sage. 
Cytrynbaum, S., \& Noumair, A. (2004). Group dynamics, organizational irrationality, and social complexity: Group relations reader 3. Jupiter: A.K. Rice.

Czander, W. M. (1993). The psychodynamics of work and organizations - theory and application. New York: Guilford Press.

Denzin, N.K., \& Lincoln, Y.S. (2005). The Sage handbook of qualitative research. London: Sage.

Diamond, M.A., \& Allcorn, S. (2004). Moral violence in organisations: Hierarchic dominance and the absence of potential space. Organisational \& Social Dynamics, 4(1), 22-45. http://dx.doi.org/10.1177/0018726704042713

Diamond, M.A., \& Allcorn, S. (2009). Private selves in public organizations - The psychodynamics of organizational diagnosis and change. New York: Palgrave Macmillan.

Diamond, M.A., Allcorn, S., \& Stein, H.F. (2004). The surface of organizational boundaries: A view from psychoanalytic object relations theory. Human Relations, $57(1), 31-53$.

Diamond, M.A., Stein, H.F., \& Allcorn, S. (2002). Organizational silos: Horizontal organizational fragmentation. Journal of the Psychoanalysis of Culture and Society, 7(2), 280-296.

Fox, S., \& Spector, P.E. (2005). Counterproductive work behaviour. Investigations of actors and targets. Washington: APA. http://dx.doi.org/10.1037/10893-000

Freud, F. (1921). Group psychology and the analysis of the ego. Complete works of Sigmund Freud. London: Hogarth.

Gabelnick, F., \& Carr, A.W. (1989). Contributions to social and political science. Jupiter: A.K. Rice Institute.

Gabriel, Y. (1999). Organizations in depth. Thousand Oaks: Sage.

Geertz, C. (2000). Interpretation of cultures. New York: Basic.

Gould, L.J., Stapley, L.F., \& Stein, M. (2001). The systems psychodynamics of organisations. London: Karnac.

Gould, L.J., Stapley, L.F., \& Stein, M. (2004). Experiential learning in organizations. Application of the Tavistock Group Relations Approach. London: Karnac.

Greenberg, J., \& Baron, R.A. (2003). Behavior in organizations. (8th edn.). Thousand Oaks: Upper Saddle River.

Grier, S., \& Rohit, D. (2001). Social dimensions of consumer distinctiveness: The influence of social status on group identity and advertising persuasion. Journal of Marketing Research, 38(2), 216

Gurim, P., \& Nagda, B.A. (2006). Getting to the What, How, and Why of Diversity on Campus. Educational Researcher, 35(1), 20. http://dx.doi. org/10.3102/0013189X035001020

Gupta, S., \& Ogden, D.T. (2009). To buy or not to buy? A social dilemma perspective on green buying. Journal of Consumer Marketing, 26(6), 376.

Hartnett, S.P.D. (2007). Does Peer Group Identity Influence Absenteeism in High School Students? High School Journal, 91(2), 35. http://dx.doi.org/10.1353/ hsj. 2008.0000

Hatch, M.J., \& Schultz, M. (2002). The dynamics of organizational identity. Human Relations, 55(8), 989. http://dx.doi.org/10.1177/0018726702055008181

He, H., \& Baruch, Y. (2009). Transforming organizational identity under institutional change. Journal of Organizational Change Management, 22(6), 575. http://dx.doi. org/10.1108/09534810910997014

Heaven, P.C.L. (1999a). Attitudes toward women's rights: Relationships with social dominance orientation and political group identities. Sex Roles, 41(7/8), 605. http://dx.doi.org/10.1023/A:1018851606423

Heaven, P.C.L. (1999b). Group identities and human values. Journal of Socia Psychology, 139(5), 590. http://dx.doi.org/10.1080/00224549909598419

Hinshelwood, R., Robinson, S., \& Zarate, O. (1997). Introducing Melanie Klein. Cambridge: Icon Books.

Hirschhorn, L. (1997). Reworking authority. Leading and following in the post-modern organisation. London: MIT.

Hollway, W., \& Jefferson, T. (2010). Doing qualitative research differently. Free association, narrative and the interview method. London: Sage.

Huffington, C., Armstrong, A., Halton, W., Hoyle, L., \& Pooley, J. (2004). Working below the surface. The emotional life of contemporary organisations. London: Karnac

Hunt, J. (1989). Psychoanalytic aspects of fieldwork. London: Sage.

James, M. (1977). Techniques in transactional analysis for psychotherapists and counsellors. Reading: Addison-Wesley.

Jaques, E. (1970). Work, creativity and social justice. New York: International Universities Press.

Kaeter, M. (1993). The age of the specialised generalist. Training, 30(1), 48-53.

Klein, L. (2005). Working across the gap. The practice of social sciences in organisations. London: Karnac.

Klein, M. (1948). Contributions to psychoanalysis, 1921-1945. London: Hogarth Press.

Klein, M. (1997). Envy and gratitude and other works 1946-1964. London: Vintage.

Kovoor-Misra, S. (2009). Understanding perceived organizational identity during crisis and change. Journal of Organizational Change Management, 22(5), 494. http:// dx.doi.org/10.1108/09534810910983460

Lawrence, W.G. (1999). Exploring individual and organisational boundaries. A Tavistock open systems approach. London: Karnac.

Levinson, H. (2002). Organizational assessment. Washington: APA

Lipponen, J., \& Leskinen, J. (2006). Conditions of contact, common in-group identity, and in-group bias toward contingent workers. Journal of Social Psychology $146(6), 671$
Lowman, R.L. (2002). The handbook of organizational consulting Psychology. San Francisco: Jossey-Bass.

Mali, A.M. (2006). The formation and development of individual and ethnic identity: insights from psychiatry and psychoanalytic theory. American Journa of Psychoanalysis, 66(3), 211. http://dx.doi.org/10.1007/s11231-006-9018-2, PMid:16964540

Menzies, I.E.P. (1993). The functioning of social systems as a defence against anxiety London: Tavistock.

Meyer, J.P., Bartunek, J.M., \& Lacey, C.A. (2002). Identity change and stability in organizational groups: A longitudinal investigation. International Journal of Organizational Analysis, 10(1), 4.

Miller, E.J. (1993). From dependency to autonomy: Studies in organization and change. London: Free Association.

Neumann, J.E., Kellner, K., \& Dawson-Shepherd, A. (1997). Developing organisational consultancy. London: Routledge.

Newton, J., Long, S., \& Sievers, B. (2006). Coaching in depth. The organisational role analysis approach. London: Karnac.

Noels, K.A., \& Clement, R. (1996). Communicating across cultures: social determinants and acculturative consequences. Canadian Journal of Behavioural Science, 28(3), 214. http://dx.doi.org/10.1037/0008-400X.28.3.214

Obholzer, A., \& Roberts, V.Z. (1994). The unconscious at work. London: Routledge. http://dx.doi.org/10.4324/9780203359860

Purdie-Vaughns, V., \& Eibach, R. (2008). Intersectional invisibility: The distinctive advantages and disadvantages of multiple subordinate-group identities. Sex Roles, 59(5-6), 377. http://dx.doi.org/10.1007/s11199-008-9424-4

Randel, A.E. (2002). Identity salience: A moderator of the relationship between group gender composition and work group conflict. Journal of Organizational Behavior 23(6) 749-766.

Reza, E. (2009). Identity constructs in human organizations. Business Renaissance Quarterly, 4(3), 77

Sato, T. (2010). Organizational identity and symbioticity: Parco as an urban medium. Journal of Management History, 16(1), 44. http://dx.doi. org/10.1108/17511341011008304

Schafer, R. (2003). Insight and interpretation. The essential tools of psychoanalysis. London: Karnac.

Speziale-Bagliacca, R. (2004). Revenge, remorse and responsibility after Freud. New York: Brunner-Routledge.

Stake, R. (1995). The art of case study research. Thousand Oaks. Sage.

Stapley, L.F. (2006). Individuals, groups and organisations beneath the surface. London: Karnac.

Stark-Rose, R., Lokken, J., \& Zarghami, F. (2009). Increasing awareness of group privilege with college students. College Student Journal, 43(2), 537.

Stein, H.F. (1987). Developmental time, cultural space. Norman: University of Oklahoma Press.

Stone, F. (2004). Deconstructing silos and supporting collaboration. Employment Relations Today, 31(1), 11. http://dx.doi.org/10.1002/ert.20001

Swann, W.B., Kwan, V.S.Y., Polzer, J.T., \& Milton, L.P. (2003). Waning of stereotypic perceptions in small groups: Identity negotiation and erosion of gende expectations of women. Social Cognition, 21(3), 194.

Sy, T., \& Cote, S. (2004). Emotional intelligence: A key ability to succeed in the matrix organization. The Journal of Management Development, 23(5/6), 437. http:// dx.doi.org/10.1108/02621710410537056

Terre Blanche, M., Durrheim, K., \& Painter, D. (2006). Research in practice. Applied methods for the social sciences. Cape Town: UCT Press. http://dx.doi.org/10.1111/ j.1548-1433.2008.00042.

Torres-Rouff, C. (2008). The influence of Tiwanaku on life in the Chilean Atacama: Mortuary and bodily perspectives. American Anthropologist, 110(3), 325. http:// dx.doi.org/10.1111/j.1548-1433.2008.00042.x

Turquet, P.M. (1974). Leadership: The individual and the group. In G.S. Gibbard, J. Harman \& L. Wells (Eds.), Analysis of groups (pp. 349-371). San Francisco: JosseyBass.

Vansina, L.S., \& Vansina-Cobbaert, M. (2008). Psychodynamics for consultants and managers. From understanding to leading meaningful change. Chichester: WileyBlackwell.

Van Manen, M. (1990). Researching lived experience. Toronto: State University of New York.

Volkan, V. (2009). Large-group identity: 'Us and them' polarizations in the internationa arena. Psychoanalysis, Culture \& Society, 14(1), 4. http://dx.doi.org/10.1057/ pcs.2008.50

Von Bertalanffy, L. (1968). General systems theory: Foundations, development, applications. New York: George Braziller.

Wade, J.C., \& Brittan-Powell, C.S. (2000). Male reference group identity dependence: Support for construct validity. Sex Roles, 43(5/6), 323

Weisbord, M., \& Janoff, S. (2005). Faster, shorter, cheaper may be simple; it's never easy. The Journal of Applied Behavioral Science, 41(1), 70. http://dx.doi. org/10.1177/0021886304273248

Wells, L. (1980). The group-as-a-whole: A systemic socio-analytical perspective on interpersonal and group relations. In C.P. Alderfer, \& C.L. Cooper (Eds.), Advances in experiential social processes (pp. 165-198). Washington DC: A.K. Rice Institute.

Whetten, D.A. (2006). Albert and Whetten Revisited: Strengthening the concept of organizational identity. Journal of Management Inquiry, 15(3), 219. http://dx.doi org/10.1177/1056492606291200

Yount, K.M. (2004). Symbolic gender politics, religious group identity, and the decline in female genital cutting in Minya, Egypt. Social Forces, 82(3), 1063. 